\title{
Numerical Simulation of Stress-Strain State Near Crack Tip in a Compact Tensile Specimen
}

\author{
A. A. Kotlyarenko, T. A. Prach, V. V. Kharchenko, and A. Yu. Chirkov
}

Pisarenko Institute of Problems of Strength, National Academy of Sciences of Ukraine, Kiev, Ukraine

\begin{abstract}
A computational scheme has been developed and a numerical simulation of the stress-strain state near the crack tip is performed at different levels of the stress intensity factor using a compact tensile specimen as an example. The authors analyze the influence of the finite element size near the crack tip and compare the results obtained in different codes (software packages) for different crack geometries.
\end{abstract}

Keywords: crack tip, stress-strain state, numerical simulation, finite element method.

Introduction. Assessment of the stress-strain state (SSS) near the crack tip is one of the most important elements in calculating strength and residual life of structural components containing flaws. There are different approaches applied in international engineering practice to study the crack-tip SSS as well as to improve the accuracy and reliability of the data obtained.

In particular, a numerical method of remeshing the crack tip region was developed in order to get more accurate data on the fracture mechanics parameters [1]. Neimitz et al. [2] propose an alternative formulation of the Ritchie-KnottRice local fracture criterion which accounts for the analyzed features of the stress distribution near the tip of a blunted crack in an elastic-plastic material. The authors of this research numerically simulated the growth of a blunted crack for different crack geometries and also studied the effect of the crack tip radius and the ratio of the specimen width to the crack length. The effects of the specimen and crack geometries were also considered elsewhere [3-5].

The present study is focuses on constructing computational models for specimens containing a crack and on improving the accuracy of the crack-tip SSS data using, by way of example, a compact tensile (CT) specimen subjected to loading followed by unloading. It also analyzes the relation between the data obtained and the model conditions, including crack geometry and finite element size in the vicinity of the crack tip.

Computational Scheme. The numerical simulation of a cracked CT specimen was performed by the finite element method using the commercial software package ANSYS and an software package RELAX [6]. The problem was solved using a 2D elastic-plastic model of a kinematically hardening material, with the model parameters determined from special-purpose experiments for a hightemperature steel 15Kh2NMFA (Fig. 1).

Based on symmetry, we specified only half of the specimen in the crack-tip SSS calculations. The geometric dimensions of a 11-mm-thick CT specimen modeled are given in Fig. 2. The crack of length $5 \mathrm{~mm}(a / w=0.57)$ was 
represented by two geometries: a mathematical cut and a cut with a rounded tip. The radius of the rounded tip was $0.2 \mu \mathrm{m}$.

The specimen under study was divided into plane quadratic finite elements (FE). Examples of the finite element meshes with different crack geometries are presented in Fig. 3. When analyzing the SSS, we made use of meshes with different FE sizes near the crack tip: $0.2,1,10$, and $50 \mu \mathrm{m}$.
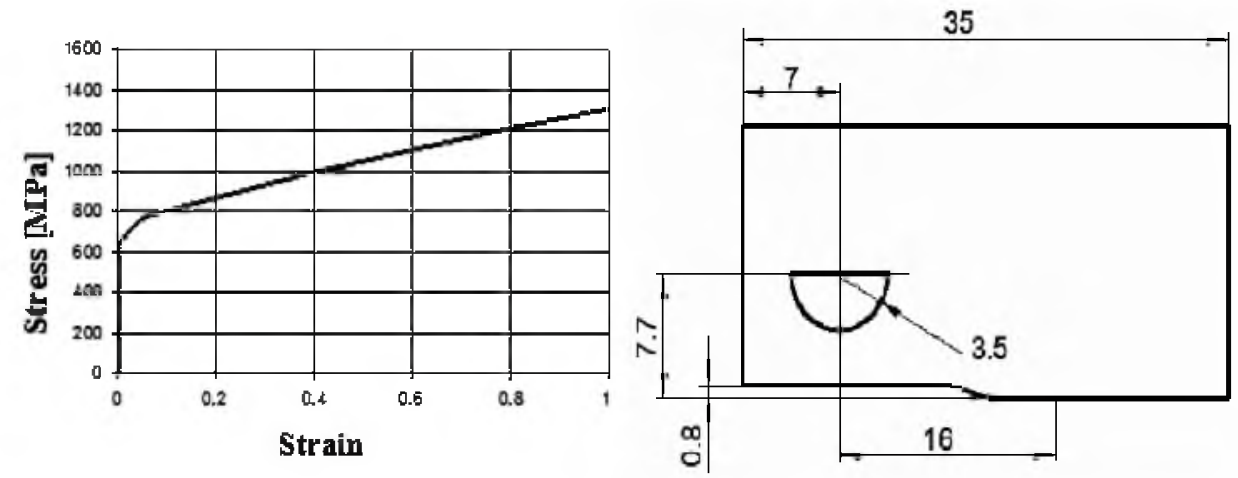

Fig. 1. Stress-strain curve.

Fig. 2. Scheme of a compact tensile specimen.

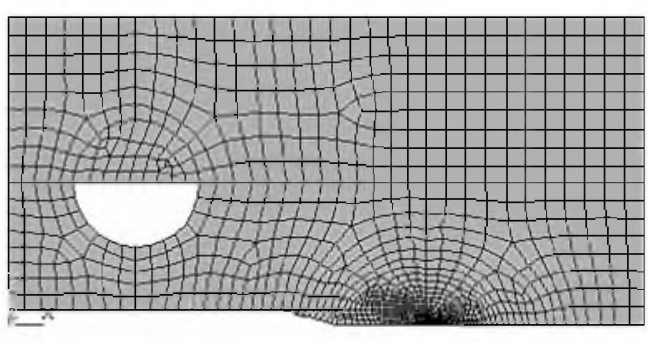

a

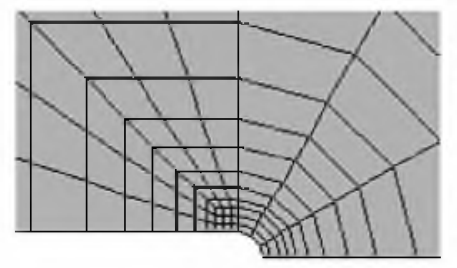

b

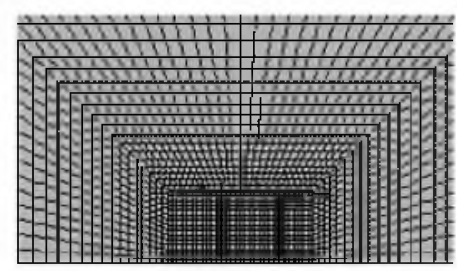

$\mathrm{c}$

Fig, 3. Finite element meshes: CT specimen (a), crack in the form of a cut with a rounded tip (b), and crack in the form of a mathematical cut (c).

The calculations were carried out for a constant temperature and the stress intensity factors (SIF) 25,30 , and $50 \mathrm{MPa} \sqrt{\mathrm{m}}$, which correspond to applied loads of $48.4,58.2$, and $96.9 \mathrm{MPa}$. To determine the SIF from the applied load, we used the known relations as per the ASTM E 1820-01 standard [7]. Unloading was modeled by applying zero pressure.

Analysis of Results. The numerical simulation yielded the crack-tip stress and strain distributions and the crack opening displacements in a CT specimen for different levels of the applied load followed by unloading to zero, crack geometries, and $\mathrm{FE}$ sizes. 
Figure 4 presents curves of normal stress vs. FE size for the crack in the form of the mathematical cut at $K_{\mathrm{I}}=30 \mathrm{MPa} \sqrt{\mathrm{m}}$. As seen from the curves, reducing the FE size brings about an increase in the maximum normal stress and a decrease of the distance from the crack tip to the normal stress maximum. For the meshes with $\mathrm{FE}$ sizes of 50 and $10 \mu \mathrm{m}$, the maximum normal stress is 1590.3 and $1919 \mathrm{MPa}$ at the distances from the crack tip 50 and $10.5 \mu \mathrm{m}$, respectively. On the other hand, for the FE sizes of 1 and $0.2 \mu \mathrm{m}$ the normal stress reaches its maximum at the distances from the crack tip 7.05 and $7.17 \mu \mathrm{m}$, respectively, and its values differ insignificantly: 2111.1 and $2123 \mathrm{MPa}$. The nature of the stress distribution in the immediate vicinity of the crack tip, the value of the maximum stress, and the distance to the maximum are almost independent of the FE size if it is below several microns or, in other words, less than the crack opening displacement. In the region of decreasing normal stresses as we move away from the crack tip, a weak effect of the FE size on the shape of the normal stress distribution curves is observed only when the distance from the crack tip is about 1.5-2 times the size of the finite elements used.

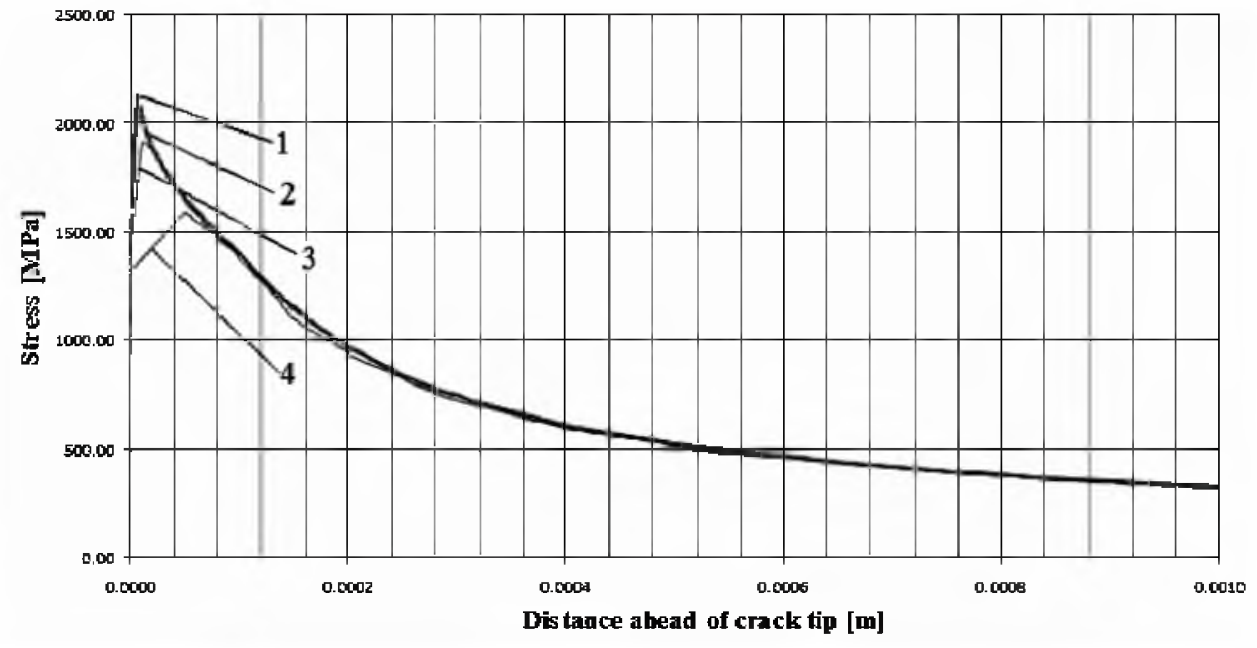

Fig. 4. Normal stress as a function of the FE size: $0.2(1), 1$ (2), 10 (3), and $50 \mu \mathrm{m}$ (4).

Next we compare the results of modeling the CT specimen with a crack in the form of a rounded cut and a mathematical cut with a FE size of $0.2 \mu \mathrm{m}$ at the SIF values of 25 and $30 \mathrm{MPa} \sqrt{\mathrm{m}}$. A comparison between the curves in Figs. 5 and 6 suggests that the crack geometry has almost no influence on the distribution of normal stresses. The curves of equivalent strains for the cracks in the form of a rounded cut and a mathematical cut are almost coincident too (Fig. 6), the only slight differences being the level of the maximum, which is only $2.5-3 \%$ higher for the crack in the form of a mathematical cut, and the distance from the crack tip to this maximum. It is noteworthy that in the calculations by the finite strain theory the resulting strains exceed the limiting value corresponding to the distance that approximates the double crack opening displacement and continue to grow as the crack tip is approached. At the same time, as we move away from 
the crack tip, the strain distributions for both cases become almost coincident after the distance approximates the double crack opening displacement.

With an increase in the SIF from 25 to $30 \mathrm{MPa} \sqrt{\mathrm{m}}$, the normal stresses slightly rise from 2059.6 to $2074.7 \mathrm{MPa}$ for the rounded cut and from 2118.6 to $2123 \mathrm{MPa}$ for the mathematical cut, while the distance from the crack tip to the stress maximum grows from 5 to $8.5 \mu \mathrm{m}$ for the rounded cut and from 5.07 to $7.2 \mu \mathrm{m}$ for the mathematical cut.

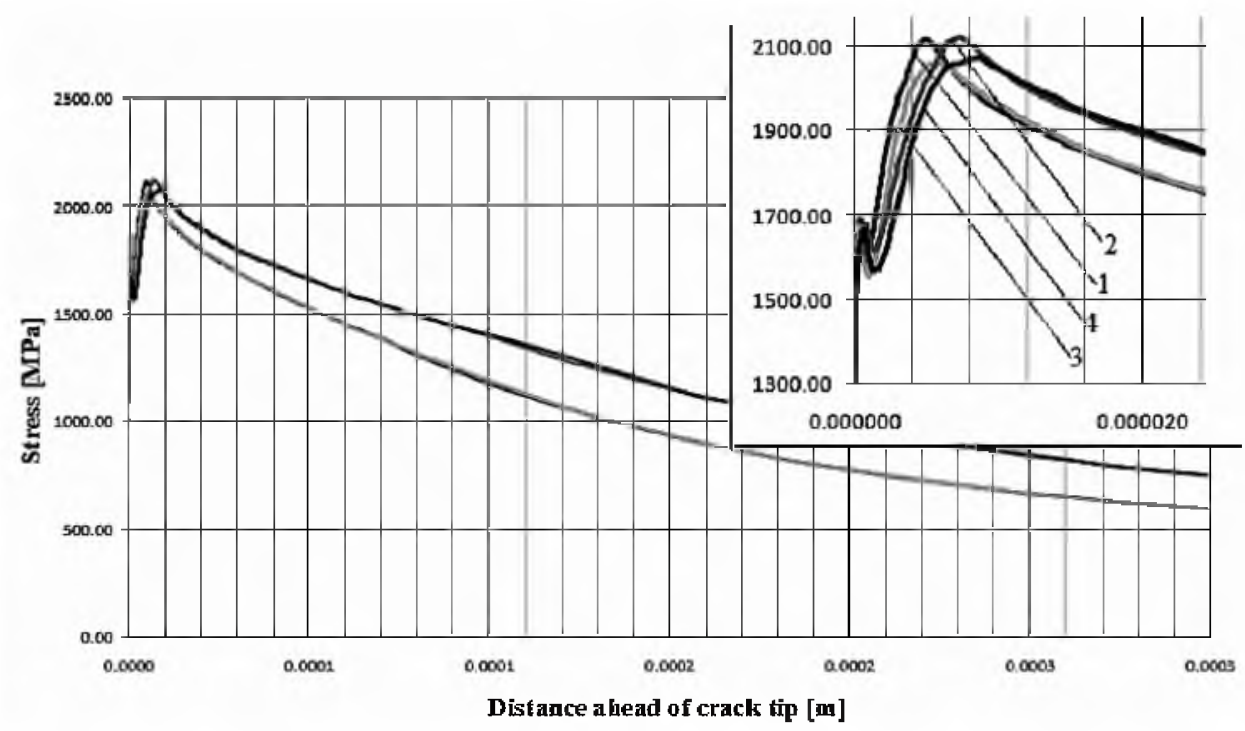

Fig. 5. Normal stress distributions for different crack geometries: (I) mathematical cut, SIF $=25$ $\mathrm{MPa} \sqrt{\mathrm{m}}$; (2) mathematical cut, $\mathrm{SIF}=30 \mathrm{MPa} \sqrt{\mathrm{m}}$; (3) rounded cut, SIF $=25 \mathrm{MPa} \sqrt{\mathrm{m}}$; (4) rounded cut, $\mathrm{SIF}=30 \mathrm{MPa} \sqrt{\mathrm{m}}$.

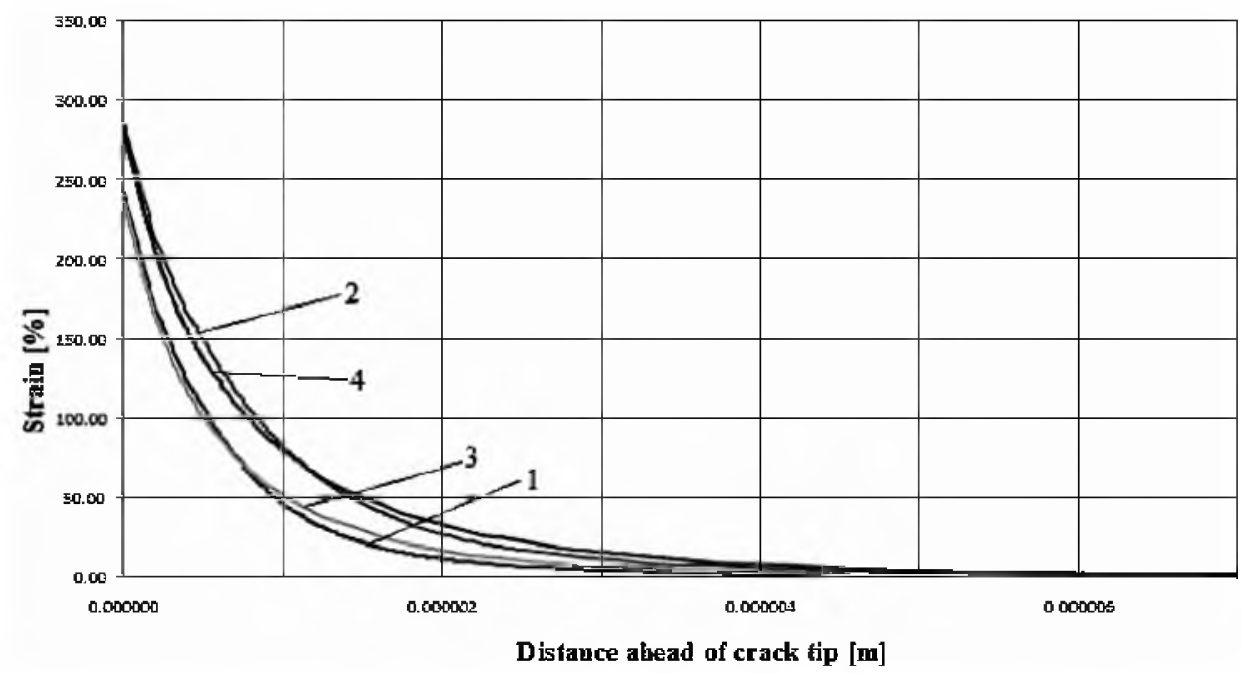

Fig. 6. Equivalent strain distributions for different crack geometries: (1) mathematical cut, SIF $=25$ $\mathrm{MPa} \sqrt{\mathrm{m}}$; (2) mathematical cut, $\mathrm{SIF}=30 \mathrm{MPa} \sqrt{\mathrm{m}}$; (3) rounded cut, $\mathrm{SIF}=25 \mathrm{MPa} \sqrt{\mathrm{m}}$; (4) rounded cut, $\mathrm{SIF}=30 \mathrm{MPa} \sqrt{\mathrm{m}}$. 
Figures 7 and 8 compare the curves of crack opening displacements for the specimen with a crack in the form of a rounded cut and a mathematical cut at the SIF values of 25 and $30 \mathrm{MPa} \sqrt{\mathrm{m}}$, which were plotted using the software packages RELAX and ANSYS, respectively. It can be seen from the figures that slight discrepancies between the results obtained by different software packages for the meshes with a minimum FE size of $0.2 \mu \mathrm{m}$ are observed only at distances from the crack tip being below $1 u \mathrm{~m}$.

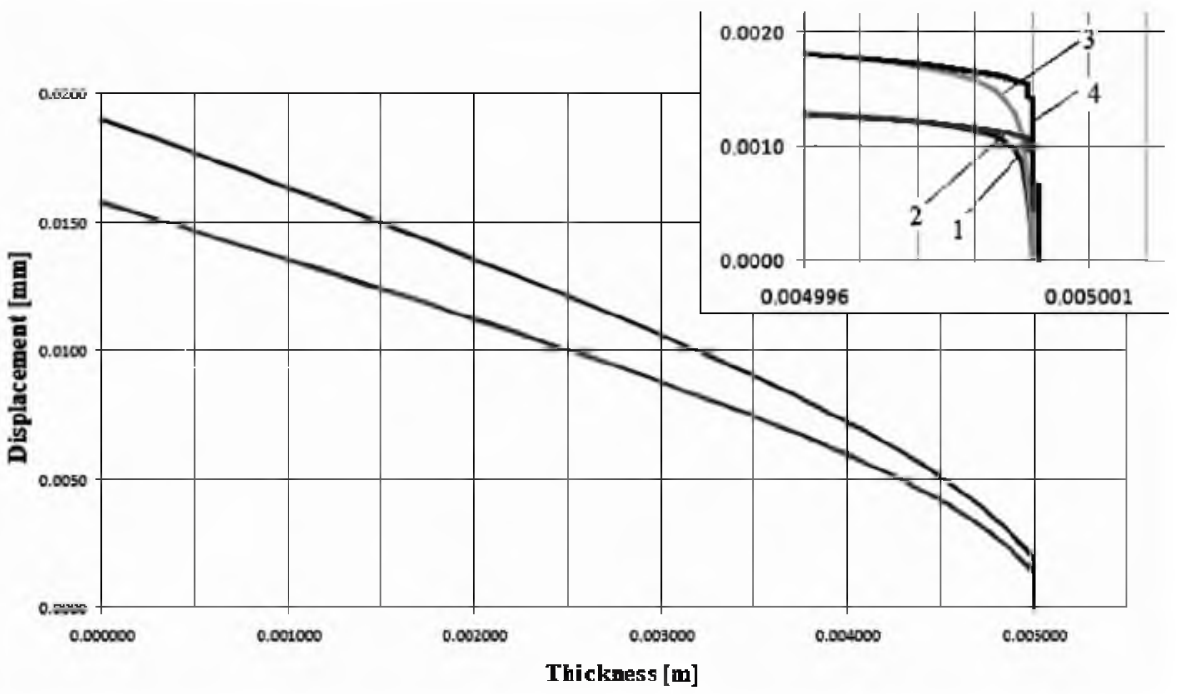

Fig. 7. Opening displacement of a crack in the form of a rounded cut: (I) RELAX, SIF $=25 \mathrm{MPa} \sqrt{\mathrm{m}}$; (2) RELAX, SIF $=30 \mathrm{MPa} \sqrt{\mathrm{m}}$; (3) ANSYS, SIF $=25 \mathrm{MPa} \sqrt{\mathrm{m}}$; (4) ANSYS, SIF $=30 \mathrm{MPa} \sqrt{\mathrm{m}}$.

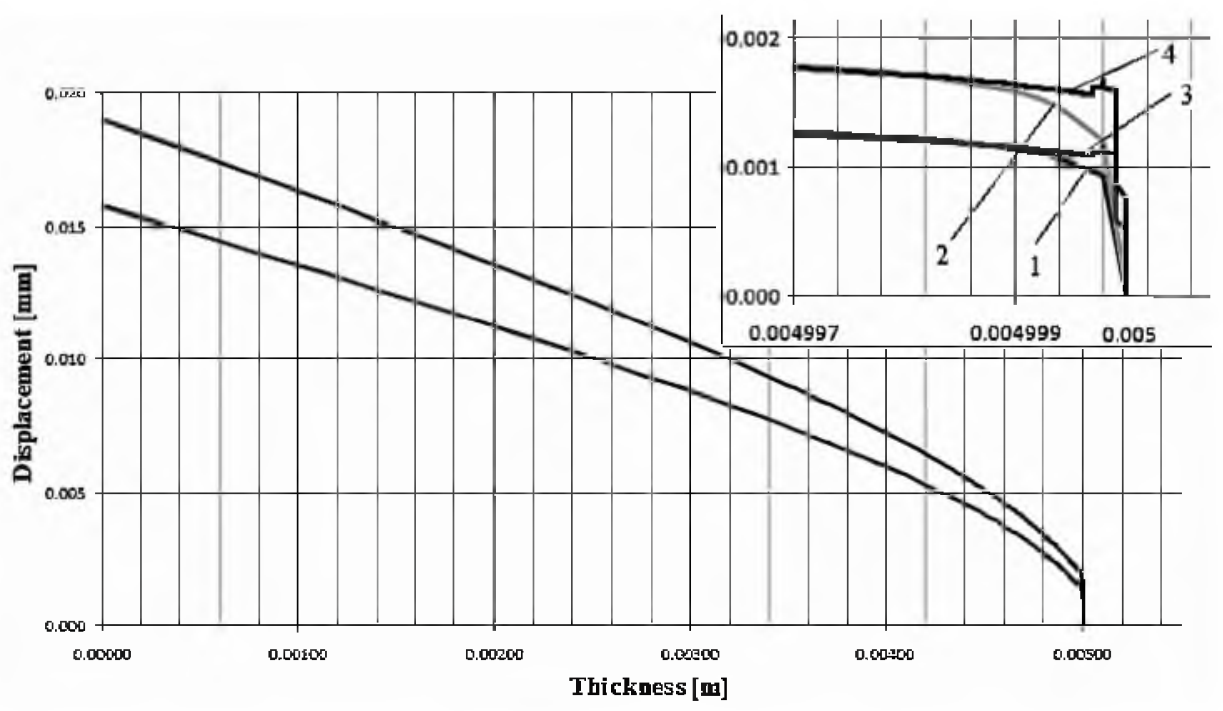

Fig. 8. Opening displacement of a crack in the form of a mathematical cut: (1) RELAX, SIF $=25$ $\mathrm{MPa} \sqrt{\mathrm{m}}$; (2) RELAX, SIF $=30 \mathrm{MPa} \sqrt{\mathrm{m}}$; (3) ANSYS, SIF $=25 \mathrm{MPa} \sqrt{\mathrm{m}}$; (4) ANSYS, SIF $=30$ $\mathrm{MPa} \sqrt{\mathrm{m}}$.

Figures 9 and 10 give the results of modeling the deformation of a CT specimen with a crack in the form of a mathematical cut under loading up to the 
SIF values of 25 and $50 \mathrm{MPa} \sqrt{\mathrm{m}}$ and subsequent unloading to zero. In the calculations we used meshes with a minimum FE size of $10 \mu \mathrm{m}$. During unloading a zone of compressive stresses arises near the crack tip. With an increase in the load from 25 to $50 \mathrm{MPa} \sqrt{\mathrm{m}}$, the zone enlarges considerably from 50 to $200 \mu \mathrm{m}$ and the maximum compressive stress grows to $1500 \mathrm{MPa}$. Further, as the load reaches $110 \mathrm{MPa} \sqrt{\mathrm{m}}$ the maximum compressive stress rises only insignificantly (to $1600 \mathrm{MPa}$ ) during unloading, whereas the distance between the maximum and the crack tip increases drastically, to about $80 \mu \mathrm{m}$, and so does the zone size, to $800 \mu \mathrm{m}$.

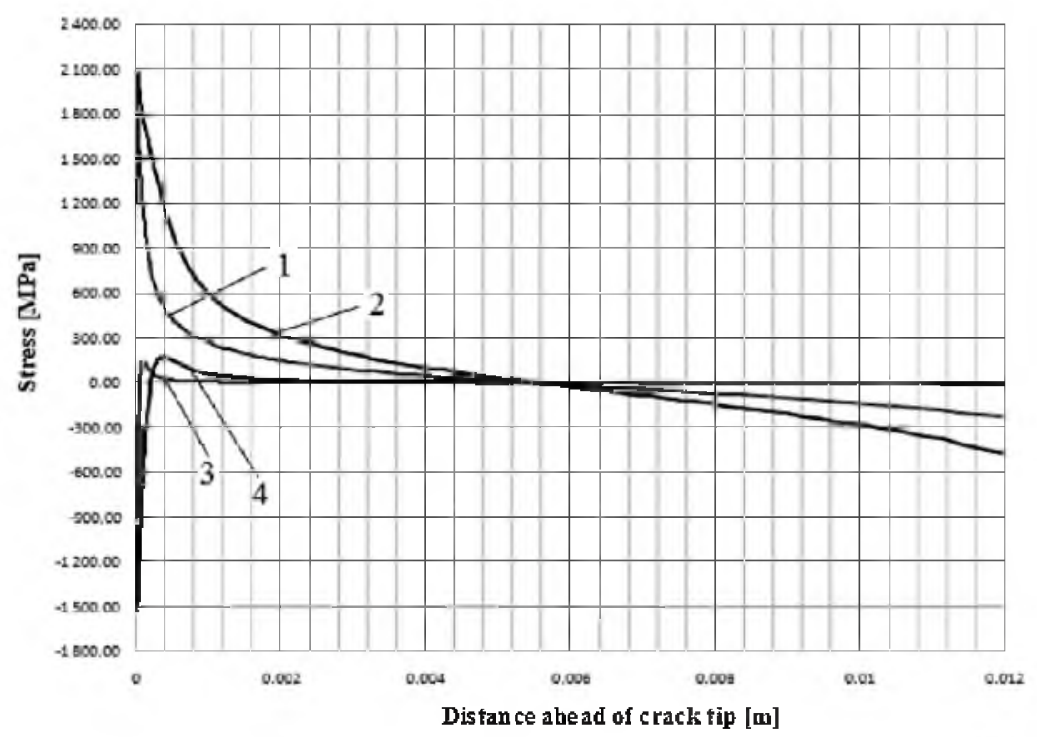

Fig. 9. Normal stress distributions in loading and unloading: (I) loading, SIF $=25 \mathrm{MPa} \sqrt{\mathrm{m}}$; (2) loading, $\mathrm{SIF}=50 \mathrm{MPa} \sqrt{\mathrm{m}} ;$ (3) unloading, SIF $=25 \mathrm{MPa} \sqrt{\mathrm{m}} ;$ (4) unloading, SIF $=50 \mathrm{MPa} \sqrt{\mathrm{m}}$.

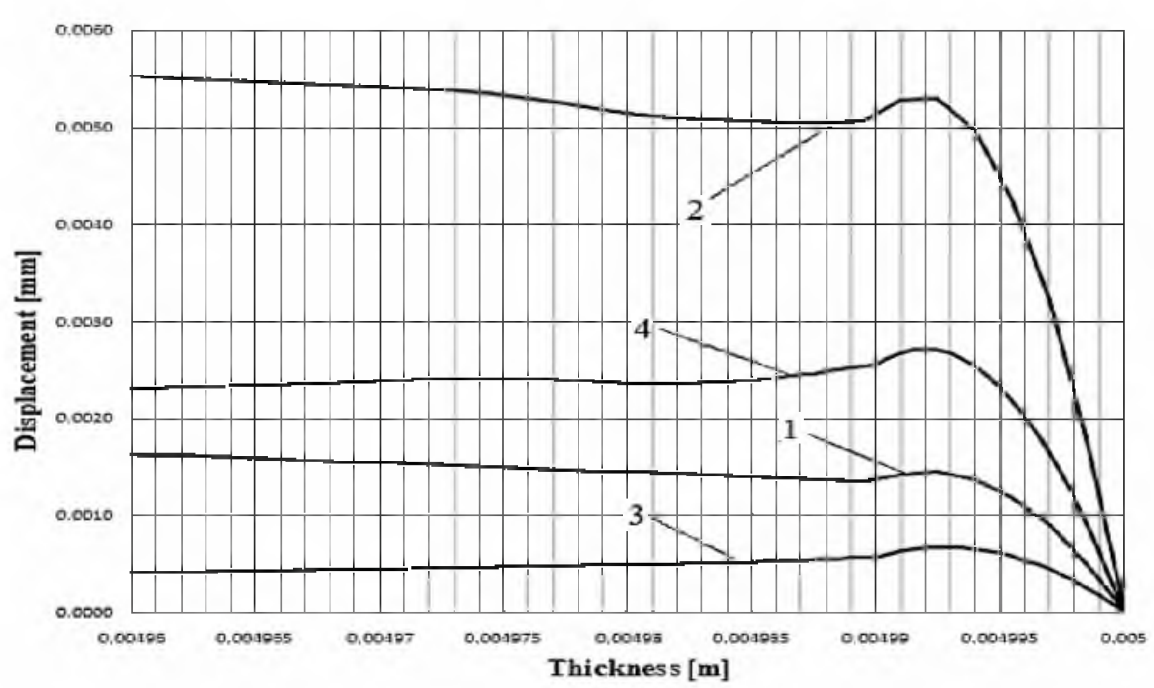

Fig. 10. Opening displacement of a crack in the form of a mathematical cut: (I) loading, SIF $=25$ $\mathrm{MPa} \sqrt{\mathrm{m}}$; (2) loading, SIF $=50 \mathrm{MPa} \sqrt{\mathrm{m}}$; (3) unloading, SIF $=25 \mathrm{MPa} \sqrt{\mathrm{m}}$; (4) unloading, SIF $=50$ $\mathrm{MPa} \sqrt{\mathrm{m}}$. 
As seen from Fig. 10, the crack opening displacement rises dramatically at distances from the crack tip up to $1 \mu \mathrm{m}$ and then grows smoothly with distance under loading, whereas during unloading it is observed to decrease somewhat with distance. This behavior is typical at the SIF values of 25 and $50 \mathrm{MPa} \sqrt{\mathrm{m}}$, but under higher loads the decrease in the crack opening displacement during unloading turns out to be more substantial because of a larger zone of plastic deformation near the crack tip.

Conclusions. We have analyzed the effect of the FE size and the crack geometry on the stress and strain distributions near the crack tip, as well as the crack opening displacement, was analyzed and the results obtained in different software packages were compared. Computational schemes where the crack is represented by a mathematical cut and the size of finite elements ranges from 1 to $10 \mu \mathrm{m}$ provide studying the SSS near the crack tip in CT specimens under loading followed by unloading to a sufficient accuracy.

1. D. Lebaillif and N. Recho, "Brittle and ductile crack propagation using automatic finite element crack box technique," Eng. Fract. Mech., 74, 1810-1824 (2007).

2. A. Neimitz, M. Graba, and J. Galkiewicz, "An alternative formulation of the Ritchie-Knott-Rice local fracture criterion," Ibid, 1308-1322 (2007).

3. S. R. Yu, Z. G. Yan, R. Cao, and J. H. Chen, "On the change of fracture mechanism with test temperature," Ibid, 73, 331-347 (2006).

4. E. Ostby, C. Thaulow, and Z. L. Zhang, "Numerical simulations of specimen size and mismatch effects in ductile crack growth. I. Tearing resistance and crack growth paths," Ibid, 74, 1770-1792 (2007).

5. E. Ostby, C. Thaulow, and Z. L. Zhang, "Numerical simulations of specimen size and mismatch effects in ductile crack growth. II. Near-tip stress fields," Ibid, 1793-1809 (2007).

6. A. Yu. Chirkov, Mixed Finite Element Scheme for Solving Boundary-Value Problems of Elasticity Theory and Small Elastic-Plastic Strain Theory [in Russian], National Academy of Sciences of Ukraine, Pisarenko Institute of Problems of Strength, Kiev (2003).

7. ASTM E1820-01 Standard. Test Method for Measurement of Fracture Toughness (2004). 